\title{
A Case of Central Perineurioma (LAZARUS and TrombetTa) of the Mandible
}

\author{
by \\ Kaoru KUSAMA, Akira IW AMOTO, Masabumi MIKUNI, \\ Masahiro KOMAG AMINE, Takao SUZUKI, Junji Y AM AMURA, \\ and Tatsuo KIMURA
}

\section{Introduction}

Benign, solitary peripheral nerve sheath tumors are generally classified into two categories:neurilemmoma (schwannoma) and neurofibroma[1]. Some histological variants of neurofibromas such as Pacinian neurofibroma by WeISER[2], nerve sheath myxoma by WEBB[3], and storiform neurofibroma by BEDNAR[4] have been reported. In 1978 LAZARUS and TROMBETTA[5] reported on a perineurioma which was characterized by proliferation of perineurial cells under electron microscopy, and placed perineuriomas including Pacinian neurofibromas and nerve sheath myxomas in the third division of solitary nerve sheath tumors. Recently we examined a perineurioma of the mandible as LAZARUS and TROMBETTA had reported. In this paper we describe the histology of our present case comprising the classification of solitary nerve sheath tumors.

\section{Case Report}

A 31-year-old female was found to have a radiolucent lesion in her left mandible on routine radiographic examination by her dentist. The patient was admitted to the Nihon University Dental Hospital in March 1980. There was no rational symptom to the lesion. No evidence of von Recklinghausen's disease in the patient or in her family was observed. She was well and clinical examinations were within normal limits except for a $52.3 \%$ albumin and a $24.3 \% \gamma$-globulin.

An extraoral examination revealed neither swelling of the left mandible nor lymphadenopaty of the submandibular region.

Intraorally the lower left first molar was missing, and the first and second premolars had metal crowns that were nontender. There was a slight swelling in the buccal vestible in the premolar region and the covering mucosa was normal in color and texture.

A panoramic radiograph revealed a well-delineated unilocular radiolucent lesion measuring approximately $3 \mathrm{~cm}$ at its greatest diameter in the left mandible. No apparent resorption of the roots of the premolars was observed. The inferior alveolar canal was not distinct (Fig. 1).

Clinical diagnosis was made as a benign cystic lesion of the mandible.

草間薰, 岩本憲, 三国誠文, 駒ヶ嶺正啓, 鈴木喬雄, 山村純二, 木村達雄：Dept. of Pathology, Nihon University School of Dentistry, 1-8-13, Surugadai Kanda, Chiyoda-ku, Tokyo 101, Japan (Director: Prof. Shinichiro Umemura) 


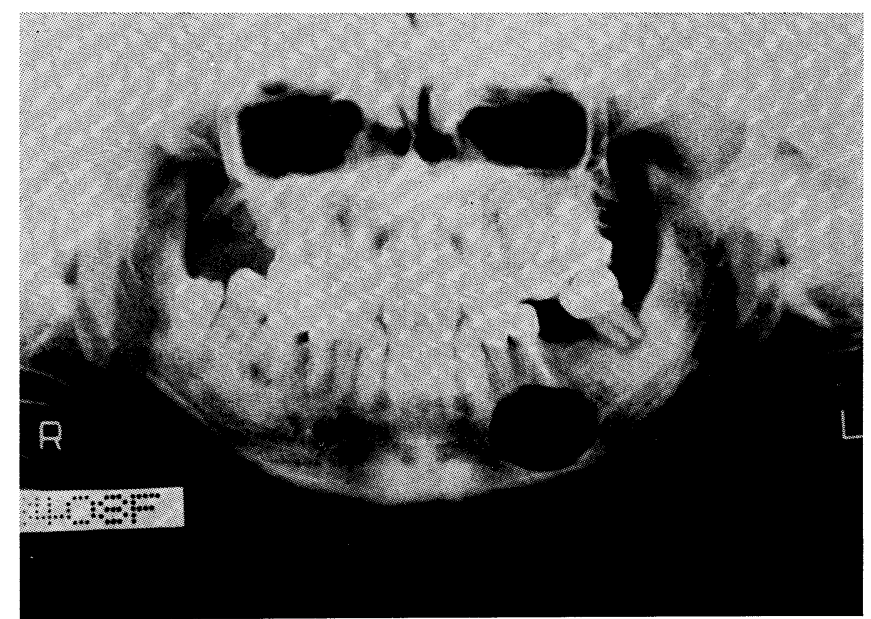

Fig. 1 Well-delineated radiolucent lesion of the left premclar area of the mandible

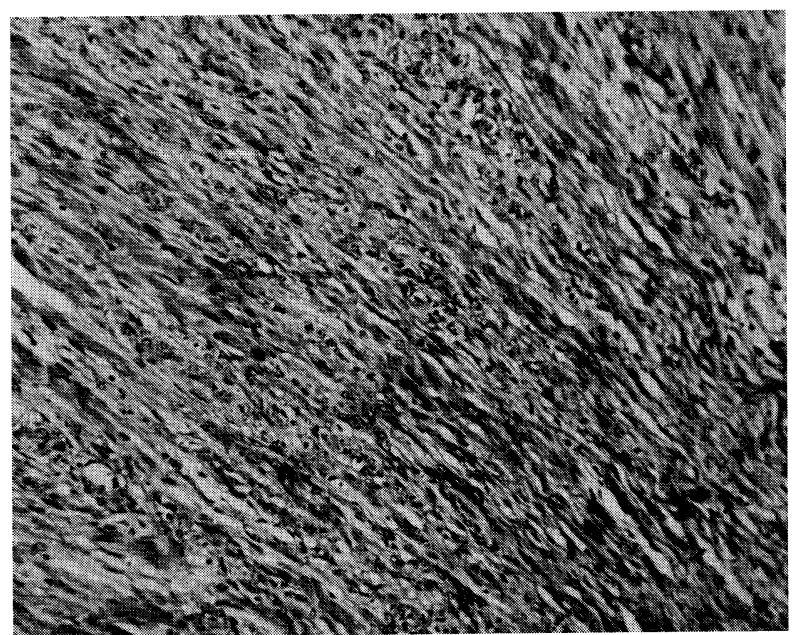

Fig. 2 Low-power view of the tumor showing a fascicular arrangement of spindle cells

At the time of operation the solid tumor was not in contact with the apex of the premolars and was related to the inferior dental nerve adjacent to the mental foramen. The tumor could be shelled out easily from the surrounding bony tissue and the bony crypt surface was smooth.

One year after the operation there is a slight presence of paresthesia of the left lower lip but no recurrence.

The surgical mass was spherical in shape with a smooth surface. It measured $2.5 \times 2.3 \times 1.3 \mathrm{~cm}$ in diameter and cut surfaces were homogenous, greyish-white in color, and exhibited neither hemorrhage nor cystic formations.

For light microscopy paraffin sections of formalin fixed tissues were stained 


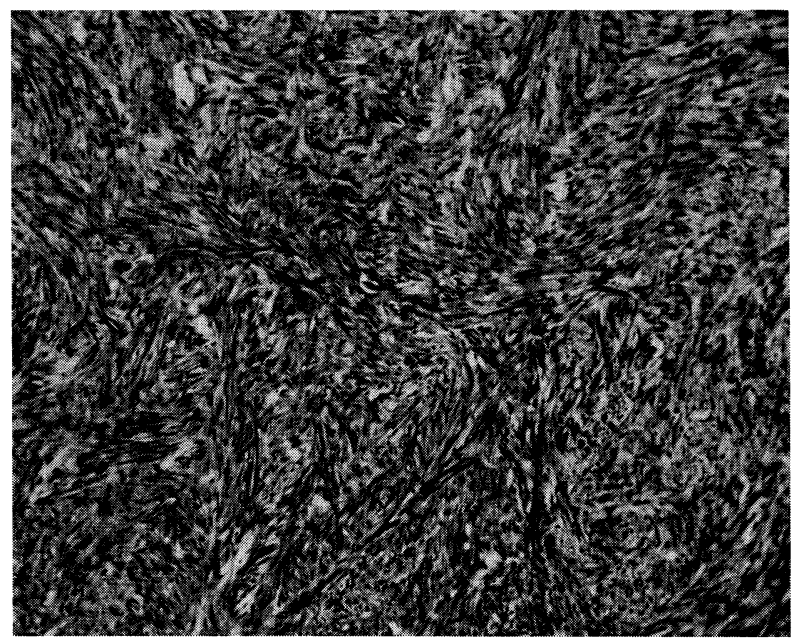

Fig. 3 Low-power view of the tumor showing a storiform-like pattern

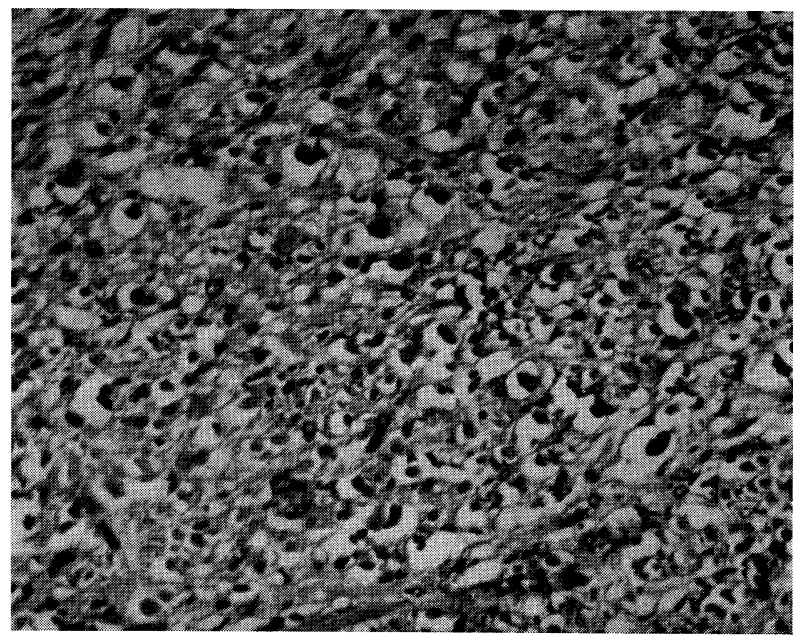

Fig. 4 Medium-power view showing the tumor cells connected with one another and collagen fibers, as dots, in the cross section

with H. E., PAS and azan Mallory. Silver impregnation was used for reticulin and Bodian for neurofibrils.

For electron microscopy the formalin fixed tissues were cut into $1 \mathrm{~mm}^{3}$ sections, washed in cacodylate buffer ( $\mathrm{pH} 7.4$ ), postfixed in $1 \%$ cacodylate buffered osmium tetroxide and then embedded in Araldite. Thin sections were stained with uranyl acetate and lead citrate and then examined using a JEM T-8 electron microscope.

\section{Light Microscopic Observation}

The tumor was not encapsulated. The tumor cells displayed a fascicular arrangement having both straight and parallel patterns (Fig. 2). Sectionally a stori- 


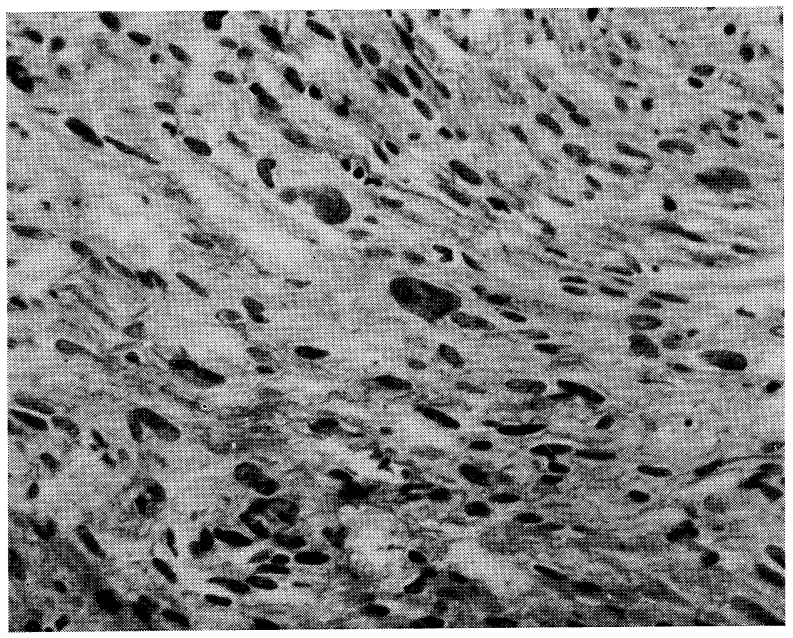

Fig. 5 High-power view of the tumor containing bizarre cells

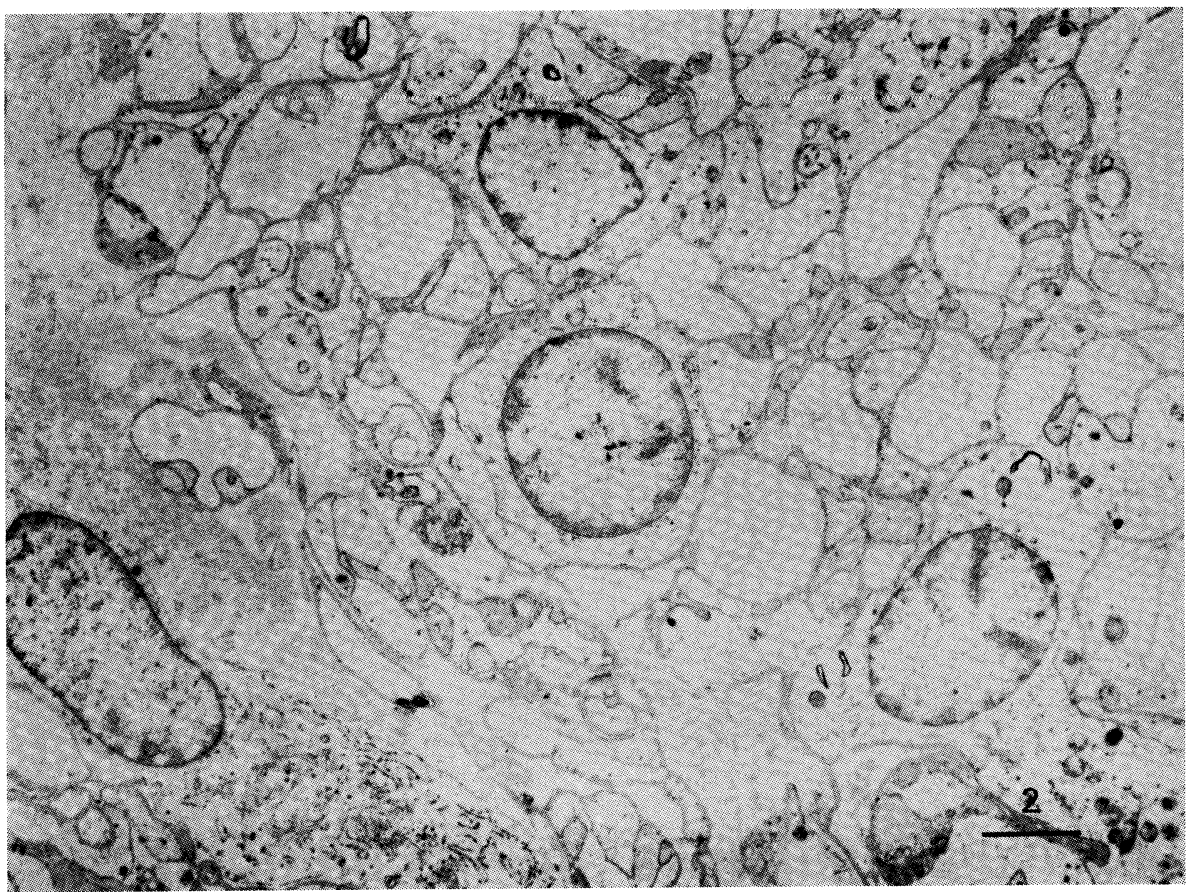

Fig. 6 Electron micrograph showing typical tumor cells with cytoplasmic processes adjoined with each other (X5000)

form-like arrangement was seen but a palisading pattern was not (Fig. 3). The tumor cells were spindle-shaped having fusiform, oval, and round nuclei with indistinct nucleoli and invariably they gave a profile of elongated and moderately abundant 


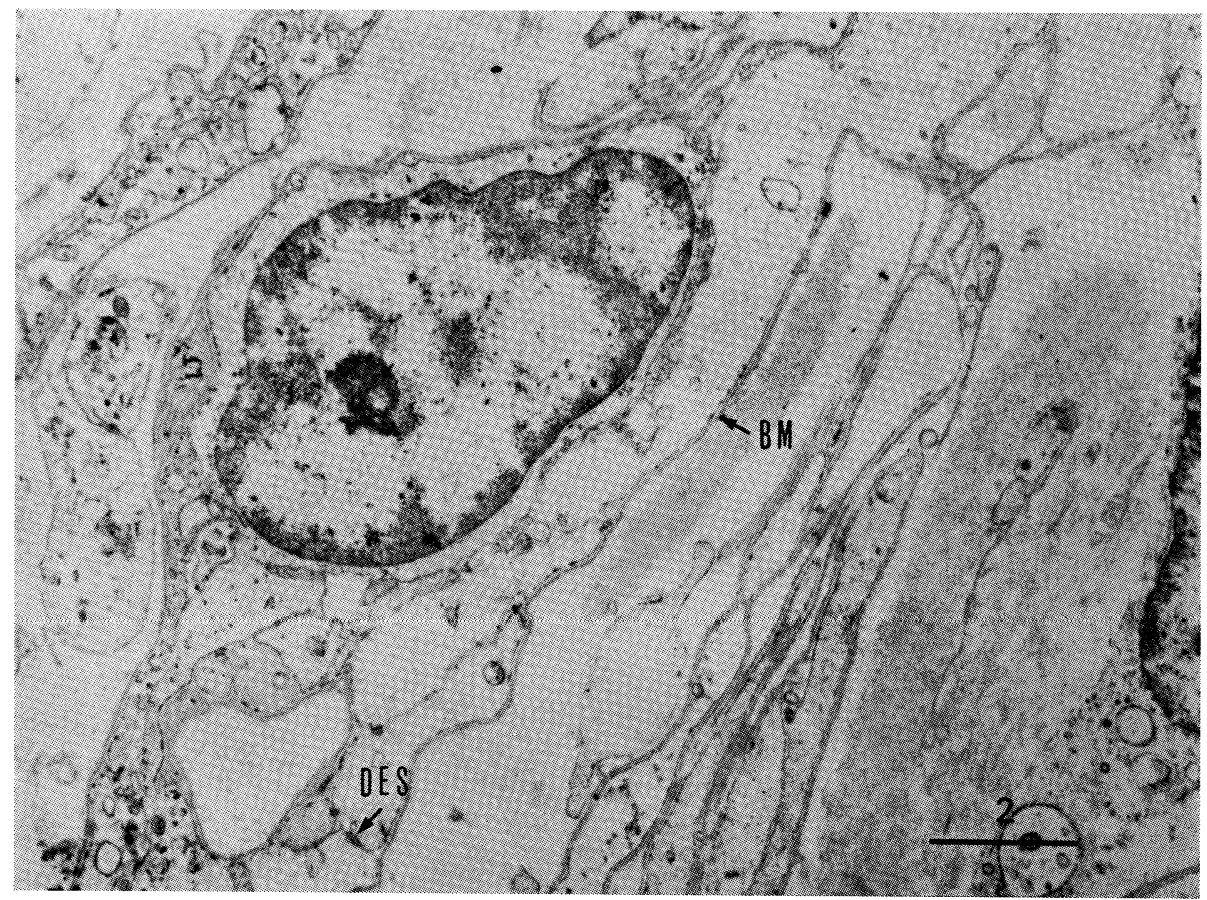

Fig. 7 Note the presence of the continuous basement membrane (BM) and desmosome (DES) (X7500)

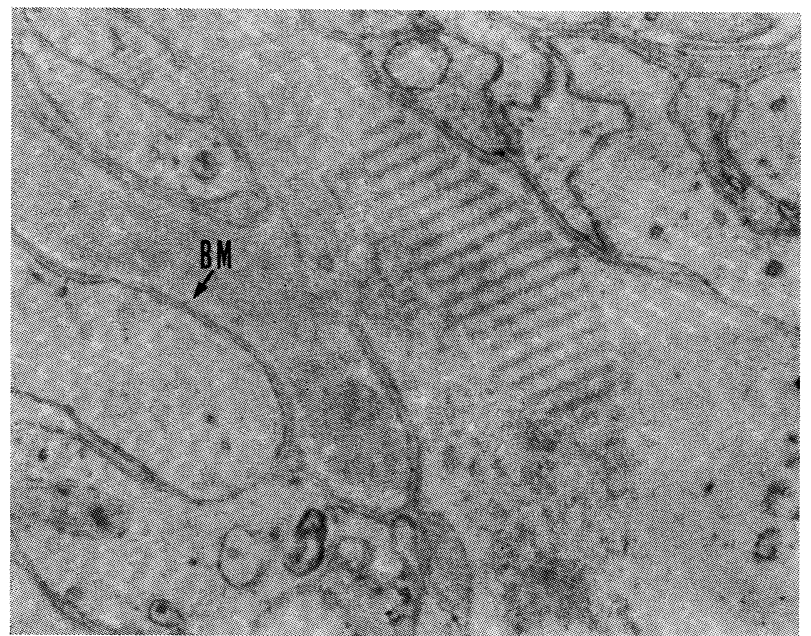

Fig. 8 Note fibrous long-spacing collagen and interrupted basement membrane (BM) (X12500)

eosinophilic cytoplasms along their long axes. The cell margins could not be clearly recognized in H. E. stained sections. In cross sections cytoplasmic processes of the tumor cells were complicatedly connected with others. Collagen fibers were seen 
between the tumor cells and were recognized as dots among the reticular tumor cells in the cross sections (Fig. 4). No nerve fibers were observed with Bodian's stain and PAS positive materials were also not detected in the intercellular spaces. While showing a slight nuclear atypism (Fig. 5), a mitotic figure was not seen.

\section{Electron Microscopic Observation}

The tumor cells were mostly spindle shaped with thin cytoplasmic processes extending along their long axes. These cytoplasmic processes were divided into secondary branches and adjoined each other (Fig. 6). Cytoplasmic organelles were generally poor. Slightly expanded r-ER, s-ER, and mitochondria were seen. Microfilaments were predominant whereas Golgi's complex was not. The plasma membrane was incompletely coated by the basement membrane and desmosomes were rarely found between bordering cytoplasmic processes (Fig. 7). Numerous pinocytotic vesicles were found along the cell surface. The intercellular spaces contained collagen fibers and rarely occurring extracellular fibrous long-spacing collagen with a cross-banding periodicity of about $1680 \AA ̊$ was observed (Fig. 8).

\section{Discussion}

Some histological variants of peripheral nerve sheath tumors such as Pacinian neurofibroma[2], nerve sheath myxoma[3], and storiform neurofibroma[4] have been reported. Pacinian neurofibroma is characterized by innumerable tactile-like structures. Nerve sheath myxoma is situated in the dermis and consists of well-defined lobules of myxomatous tissue separated by fibrous septae. Storiform neurofibroma is characterized by matting-like structures containing melanocytes and is suggested to be related to blue nevus.

The present case was not encapsulated. It consisted of a fascicular arrangement with storiform-like patterns as well as straight and parallel arrangements. Under electron microscopy the tumor cells had some characteristics of perineurial cells. The present tumor was histologically different from neurilemmoma, neurofibroma, and any variants of peripheral nerve sheath tumors except for perineurioma described by Lazarus and Trombetta[5], and INABA et al.[6].

The tumor cells of Pacinian neurofibroma, nerve sheath myxoma, and perineurioma are characterized by long cell processes, numerous pinocytotic vesicles, variable and interrupted basement membranes, and the presence of cell junctions under electron microscopy[2,3,5,6]. Perineurial cells, one of the cellular components of peripheral nerve sheaths, are shown to have similar ultrastructural features to these tumor cells. By the use of electron microscopy LASARus and TrombetTA[5] placed perineurioma including the tumors characterized by proliferation of perineurial cells in the third division of solitary nerve sheath tumors.

It is generally recognized that neoplastic cells of neurilemmoma are attributed to schwann cells[7-10], but a minority affirm a perineurial origin[11] and some proponents consider the schwann cell doctrine but do not entrirely exclude a perineurial origin[1,9]. Also neurofibromas are generally composed of schwann cells and fibroblasts. While some observers support the perineurial origin of this tumor a greater number of modern investigators suggest that neurofibromas probably are 
not neoplastic $[1,12,13]$.

The histologic difference between these two tumors concerning the amount of collagen fibers and different maturation stages in schwann cells composing these tumors has been discussed for many years by numerous inverstigators[12,14,15].

Cellular schwannoma as a variant of neurilemmomas shows nuclear atypism[1], and IDE et al.[16] reported central neurilemmoma of the jaw containing bizarre cells. There were no case reports of neurofibroma showing nuclear atypism.

We think that our case should be classified as a variant of neurilemmomas, for two reasons. First because the arrangement of the tumor cells histologically resemble Antoni type A and secondly because a slight nuclear atypism was observed.

\section{Conclusion}

The case of a 31-year-old female with a peripheral nerve sheath tumor of the left premolar region of the mandible was described. The patient was asymptomatic and the lesion appeared as a well-demarcated radiolucency. Light and electron microscopic examinations showed a perineurioma as LAZARUS and TROMBETTA have described. We think that this case should be classified as a variant of neurilemmomas on consideration of its histological features.

\section{References}

[1] Armed Forces Institute of Pathology (AFIP) 1969. Tumors of the peripheral nervous system, Atlas of tumor pathology, 2nd series, Fasc. 3, Armed Forces Institute of Pathology, Washington, D.C.

[2] Weiser, G. 1975. An electron microscopic study of "Pacinian neurofibroma". Virchows Arch. 366, 331-340.

[3] WeBb, J. N. 1979. The histogenesis of nerve sheath myxoma: report of a case with electron microscopy. J. Path., 127, 35-37.

[4] Bednar, B. 1957. Storiform neurofibromas of the skin, pigmented and nonpigmented. Cancer 10, 368-376.

[5] Lazarus, S. S. \& Trombetta, L. D. 1978. Ultrastructural identification of a perineurial cell tumor. Cancer 41, 1823-1829.

[6] Inaba, H., Hizawa, K., II, K. \& Iwasa, S. 1980. Perineurioma: a distinctive form of the peripheral nerve tumor. Tokushima J. Exp. Med., 27, 37-43.

[7] LuSE, S. A. 1960. Electron microscopic studies of brain tumors. Neurology 10, 881-905.

[8] Wechsler, W. \& Hossman, K.-A. 1965. Zur Feinstruktur menschlicher Acusticusneurinome. Beitr. Path. Anat. 132, 319-343.

[9] WAGGEnER, J. D. 1966. Ultrastructure of benign peripheral nerve tumors. Cancer, Philad. 19, 699-705.

[10] Cervos-Navarro, J., Matakas, J. \& Lazaro, M. C. 1968. Das Bauprinzip der Neurinome: Ein Beitrag zur Histogenese der Nerventumoren. Virchows Arch. Abt. A. Path. Anat. 345, 276-291.

[11] Raimandi, A. J. \& Beckman, F. 1967. Perineurial fibroblastomas: their fine structure and biology. Acta Neuropath. 8, 1-23.

[12] Shinagawa, T. 1980. Neurofibroma: its histogenesis and histopathology. Tokyo Jikeikai Med. J. 95, 621-638. (Japanese)

[13] TaKahama, M. 1963. Electron microscopic study of malignant and benign tumor of the human soft tissue. Bull. Tokyo Med. and Dent. Univ. 10, 281-331.

[14] Fisher, E. R. \& Vuzevski, V. D. 1968. Cytogenesis of schwannoma (neurilemmoma), neurofibroma, dermatofibroma and dermatofibrosarcoma as revealed by electron microscopy. Am. J. Clin. Path. 49, 141-154. 
[15] MiNCKLER, J. 1961. Supporting cell tumors of nervous system in pathology (W.A.D. Anderson, ed.) Mosby Co.

[16] Ide, F., Kani, Y., Hara, K., Nakada, M., Uchiyama, M., Umezawa, T. \& Yokokawa, T. 1977. Central neurilemmoma of the jaws: report of a case and review of the literature. J. Nihon Univ. Sch. Dent. 19, 59-65. 